\title{
Design of an Overfill Prevention System to be used in Oil Trucks; A Case Study of Kenya Pipeline Company, Eldoret Depot, Kenya
}

\author{
Joan J. Kiptarus \\ Department of Mechanical and Production Engineering, \\ Moi University, Eldoret-Kenya
}

\begin{abstract}
Oil transportation from the oil depot, has for a long time been used by rail and road, which requires a physical filling in the trucks compartments. Whenever the system is unable to prevent overfilling of the compartment, for a number of reasonshuman or machine failures, there is an uncontrolled flow of oil that leads to losses to many parties. It is therefore in the best interest of the oil vendor, and the pipeline company to find a solution to this problem. Overfill prevention of trucks in Kenya does not exist yet. Loading stations rely on accuracy of calibration of the metering gauge and the compartments. This study aims at designing an overfill protection device to avoid overflow of oil in trucks served by the Eldoret depot. The viability of different overfill control techniques was analyzed, fabrication, assembling and testing of the working of a model system was done. Designing a system that can be used in oil trucks, warn of overfill, and possibly shut off the oil flow before it becomes costly to the parties involved. This study proposes the use of a level sensing device that can either be programmed or relayed, to actuate a counter measure i.e. shut off the flow and warns of it by visible and audible alarms that will be well-placed and labeled. The working of the system was tested where it involved the design of a model to simulate the system, a float switch and relay circuit was used to which the pump was connected to. The float switch was used as an indicator of the level of petroleum in the compartment where it was drilled through the compartment at a level determined through calculation, such that it will only be used when the pre-existing measure has failed, hence serving the primary purpose of this project. When the safe level is exceeded, the float switch completes the circuit and a relay actuates the pump to stop. As this happens, the buzzer and red led are switched on which acts as the alarms. Therefore overfill is prevented and warning is given thereof.
\end{abstract}

\section{Keywords-Oil, Overfill, Design, Circuit, Model, Safety}

\section{INTRODUCTION}

Kenya Pipeline Company has the mandate to ensure efficient and safe supply and distribution of oil and gas in and outside Kenya. The Eldoret depot, for instance, has a loading station where trucks from the North Rift and Western parts of the country and even Uganda, Zambia and Rwanda come to fill oil, for the purpose of distribution. This is to say that the depot receives a good number of trucks on any one day. Loading takes place at the gantry as shown in figure 1 .

The height of the gantry is such that each compartment is easily opened and closed during loading. Arms of different types of petroleum products are painted differently for easier identification. The driver of the truck drives into the bay, and before loading occurs, earthing is done to prevent any electric faults during loading. The driver is always dressed on proper safety clothing (PPEs). He gives the person on duty their receipts showing how much products should be filled in each compartment. It is their role to take the loading arm into the respective compartment until all compartments are filled. Being the KPC's duty to ensure safety, they are therefore required to ensure that the filling is safe, for the sake of the company infrastructure and human safety. Overfilling is one of the hazards identified.

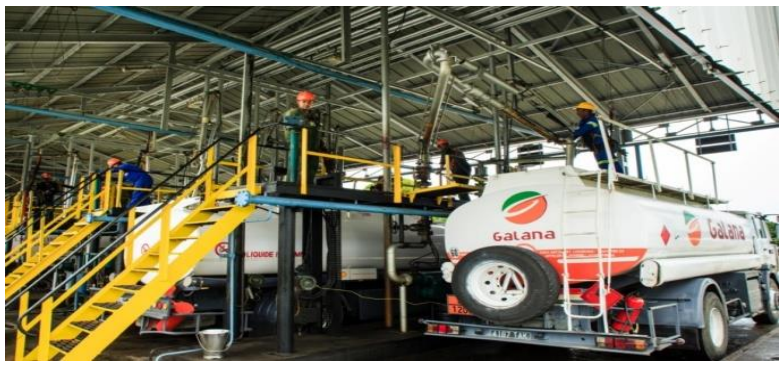

Fig. 1. Aaroad tanker being loaded at the gantry (Kpc, Eldoret depot)

Despite automation in loading the trucks, Overfilling incidents do occur. These mishaps could be the result of equipment, or human error. Some overfilling incidences occur due to miscalibration of the oil chambers. In a situation for example, where 2000 litres of oil has been set to be loaded into a 1500 litres chamber, this is an overfill situation and due to human error, the driver put the loading arm to the wrong chamber. This may lead to under filling or overfilling. Overfilling occurs if the chamber capacity is less than the set capacity. Residual oil in the tank truck compartment is another apparent reason for truck overfilling.

Equipment failure as a cause of overfill, occurs as a result of deficiencies in the loading system. This also covers the inability of the emergency stop to function properly. Where a flow control or metering valve fails and there could be little time to manage the problem before the compartment overfills. This is because compartments normally have a limited ullage of about $5 \%$ and because high flow rates can continue even if the pump has been turned off. There are also cases where the metering gauge is faulty thus giving a faulty reading. The result of overfill is an uncontrolled flow where one in every 400 fillings results is an overflow.

Safety should be considered paramount in any working environment. Oil is highly flammable and if exposed to an ignition source, can cause an explosion. This could cause massive destruction of property and the environment and the 
most tragic, injury to persons and these losses can result to hundreds of millions of Kenya Shillings.

Overfilling carries its risk, extending to the depot, all way to the truck owner, and the personnel. Some effects of overfilling include; Environmental pollution, Time wasted to flush the oil, Resources invested to restore the oil, Property damage due to fires, Injury to persons Legal consequences and Public relations problems.

This study therefore targets to do away with overfilling in loading trucks. In order to avoid such and many other problems, it is imperative to come up with a system to prevent overfilling in loading trucks. The system shall ensure up-tostandard safety in loading stations.

\section{PROPOSED MECHANISM OF THE OVERFILL PREVENTION SYSTEM}

\section{A. Design consideration}

An overfill oil prevention system was designed based on the following considerations:

1. Locally available materials were used to reduce the cost of production and maintenance

2. The design must ensure maximum capacity of oil in the tank is achieved without any spillage, hence good efficiency.

\section{B. Proposed design mechanism}

The system shall comprise of:-

\section{Float switch}

The float sensor is best suited in our application as a liquid level measurement system. It will be placed on the tank compartment wall, at $96 \%$ height to give $4 \%$ ullage. The float switch used here is a mechanical type switch. Due to the changing liquid level, the movement of the float will cause the circuit to either open or close. The material polypropylene is suitable for both water and oil

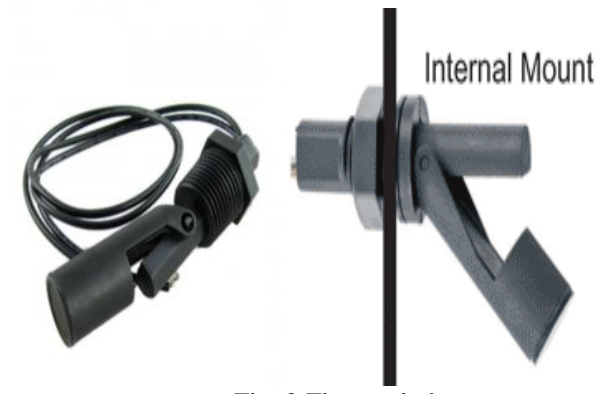

Fig. 2.Float switch

\section{2. $\quad$ Pump}

The pump used in this model is a positive displacement micropump with a heavy-duty motor and a tough thermoplastic body. The pump supports transfer and circulation. In this model, the pump will pump water/oil from source, to a bucket that represents the compartment

\section{Alarms}

They shall be strategically placed, such that the operator and the driver can see. They shall also be well labeled. In this model, the alarms will have the same source of power as the pump. When the float switch closes, an intermediate action will lead to the opening of the pump circuit to stop it and the alarms circuit will be closed. The visible alarm in our model will be a red LED- A two-lead semi-conductor light source that emits light when the junction diode is activated. The audible alarm will be a buzzer. A buzzer is an audio signaling device.
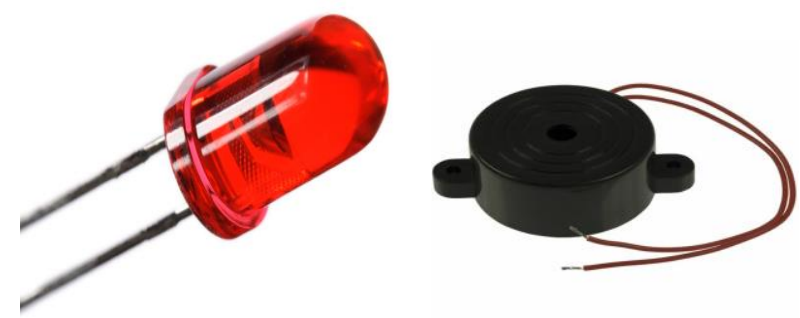

Fig. 3.Red LED and Buzzer

\section{Transformer}

The transformer's role in this model is to step down the voltage from the mains, from $220 \mathrm{~V}$ to $12 \mathrm{~V}$.

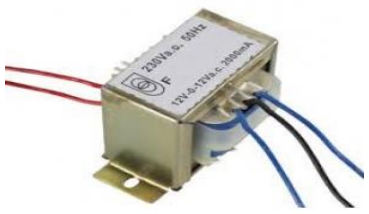

Fig. 4 Transformer

\section{Relay}

A relay is an electrically operated switch. It allows circuits to be switched by electrical equipment. A simple electromagnetic relay consists of a coil of wire wrapped around a soft iron core, an iron yoke which provides a low reluctance path for magnetic flux, a movable iron armature, and one or more sets of contacts (there are two contacts in the relay pictured). The armature is hinged to the yoke and mechanically linked to one or more sets of moving contacts. The armature is held in place by a spring so that when the relay is de-energized there is an air gap in the magnetic circuit. In this condition, one of the two sets of contacts in the relay pictured is closed, and the other set is open.

When an electric current is passed through the coil it generates a magnetic field that activates the armature and the consequent movement of the movable contact either makes or breaks (depending upon construction) a connection with a fixed contact. If the set of contacts was closed when the relay was de-energized, then the movement opens the contacts and breaks the connection, and vice versa if the contacts were open. When the current to the coil is switched off, the armature is returned by a force, approximately half as strong as the magnetic force, to its relaxed position. Usually this force is provided by a spring.

The relay used in the model is a 2-channel relay, as it only operates the circuit of the pump. 


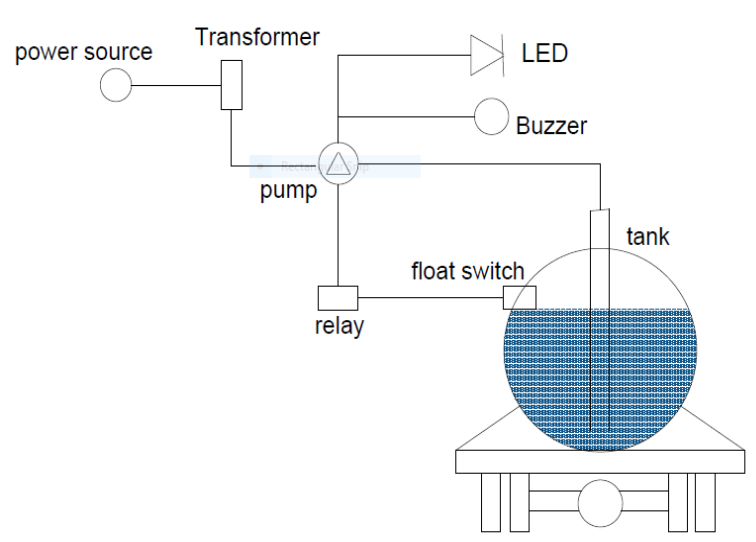

Fig. 5.Drawing layout of the proposed design mechanism

Flowchart

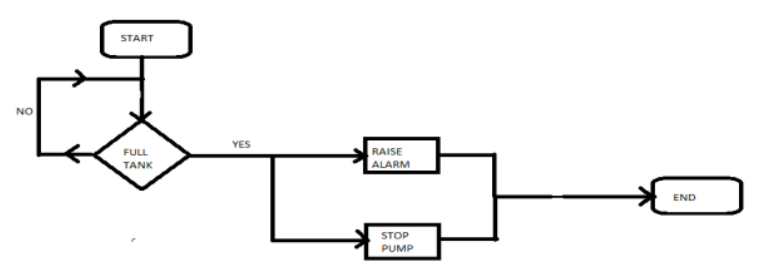

Fig. 6.Flowchart of the proposed design mechanism

Block diagram

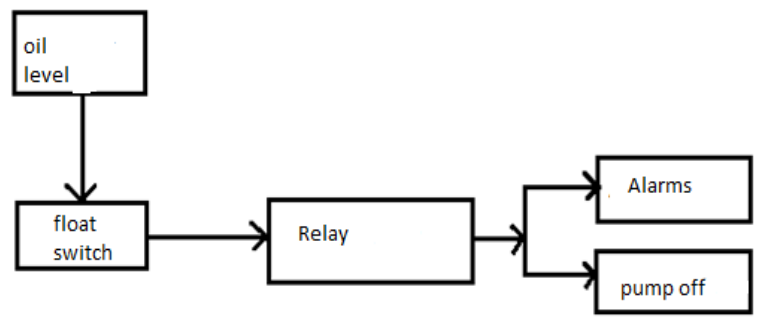

Fig. 7.Block diagram of the proposed design mechanism

\section{DESIGN OVERVIEW AND CALCULATIONS}

SW1: Float switch

SW2: Main pump switch

LED-BIRG: green LED for indication run operation

LED-RED: red LED for indicating tank full.

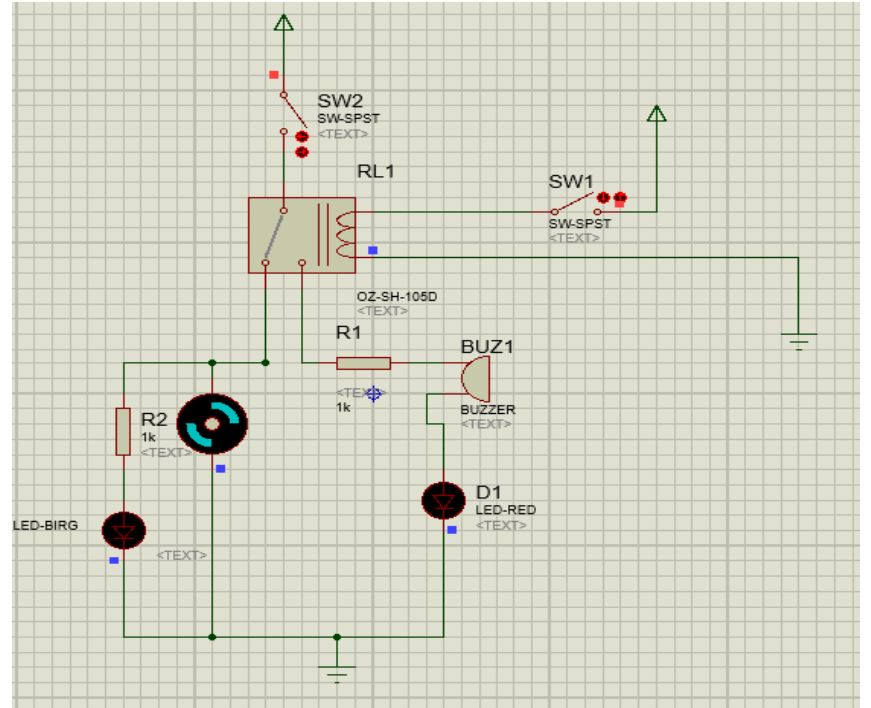

Fig. 8 Main switch off

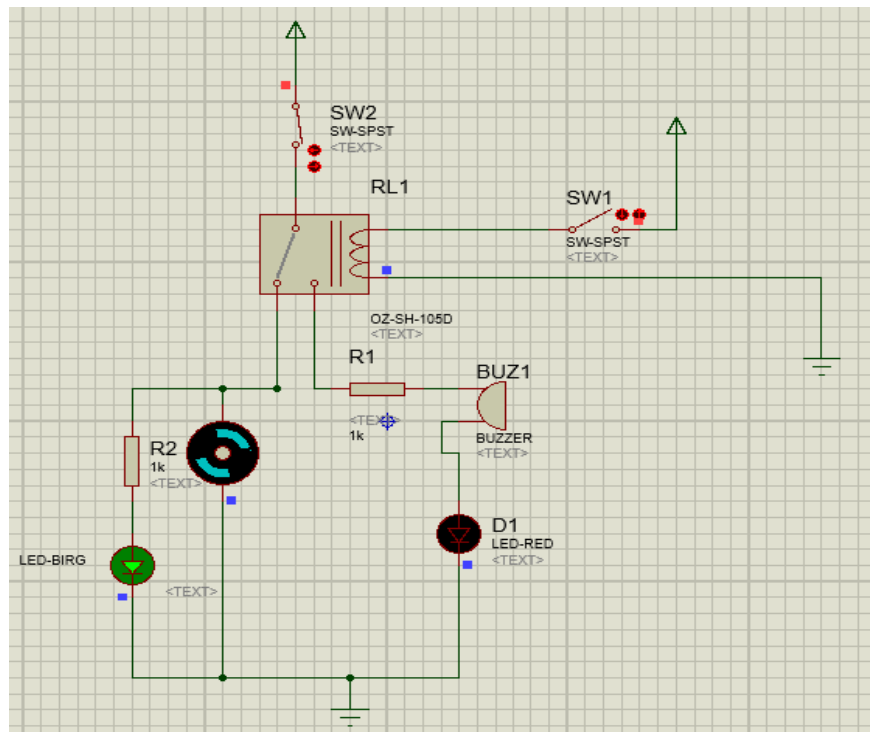

Fig. 9 Main switch on, pump running

Design calculations:

Terminal voltage $=12 \mathrm{~V}$

Load Resistance of $12 \mathrm{~V}$ pump motor $=12 \mathrm{Ohm}$

Approximated Total resistance in run mode $==11.86 \mathrm{Ohm}$

Total current $=1.012 \mathrm{~A}$ 


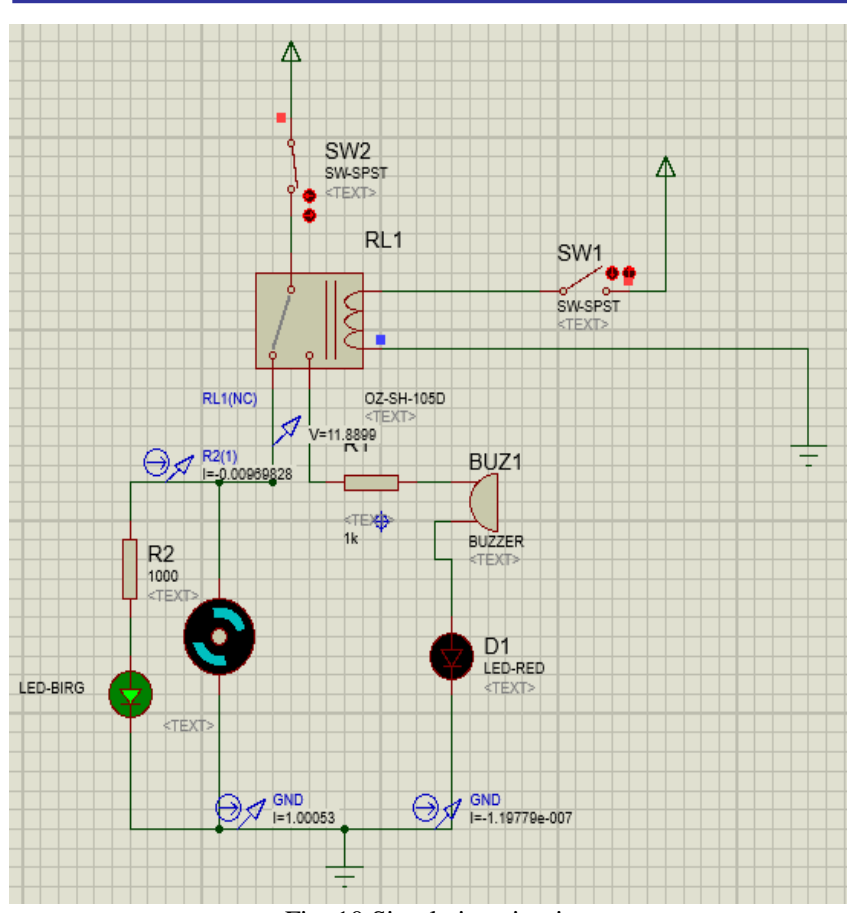

Fig. 10 Simulation circuit

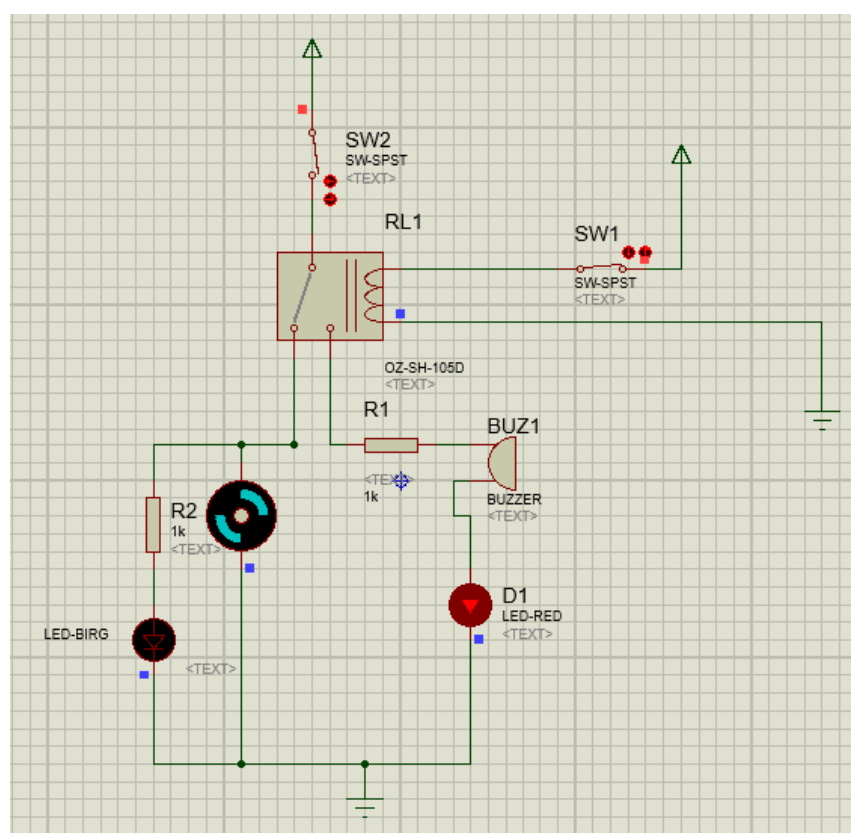

Fig. 11 Tank full, float switch on, pump off

\section{CONCLUSION}

After testing the model system, it was found that: The design is simple and appealing to the majority, It can be affordable and easy to use, it gives warning before the compartment fills, it can be automated and remote controlled for better analysis and it is flexible to accommodate future modifications. However its shortcomings includes: it is tedious since each compartment needs its own float switch and its implementation is on existing tankers which owners may be reluctant to adapt to changes.

\section{ACKNOWLEDGMENT}

The author is very grateful to the Department of Mechanical Engineering of Moi University for using their workshops and Lab facilities, KPC Eldoret and special thanks to Sheila Nasongo and Gladys Kikwai for their massive contribution in this project

\section{REFERENCES}

[1] H. Timm Electronic GmbH, Technical Description; Overfill Prevention Controller EUS-2, 22 $2^{\text {nd }}$ Nov. 2013.

[2] Jones \& Bartlet Learning LLC. MC-306/DOT-406 Cargo Tank Truck: Design, Construction and Operating Procedure.

[3] Kuwait National Petroleum Company, Local Marketing Department, Specification for Fuel Road Tankers/Semi-Trailers for Transportation of Petroleum Products, October 2008.

[4] KLM. Technology Group Rev 1, Process Design Of Loading And Unloading Facilities For Road Tankers, Project Standards And Specification, April 2011

[5] Phil Myers Emerson Process Management, The Engineer's Guide to Overfill Prevention, 2015 Ed.

[6] Massive blaze rages at fuel depot. BBC news. 12 December 2005

[7] Buncefield fire. Total. Archived from original on February 2009. Retrieved 11 December 2009.

[8] The Energy Regulatory Commission, Operation and Maintenance of Petroleum Terminals; Technical Guidance Notes. Available at www.erc.go.ke

[9] Satyajit Verma \& Freeman Self, Bechtel OG \&C Design Option For Overfill Protection For Above Ground Storage Tanks, April 2014, New Orleans L.A.

[10] The Major Incident Investigation Board, The Buncefield Incident 11 Dec 2005, A Final Report,2008

[11] NYC Mechanical Code, Chapter 13, Fuel Oil Piping and Storage, 2008

[12] Sapcon Instruments. "Flash ash level detection". Received 2016-09-22

[13] Deeter. "Float level sensors". Retrieved 2009-05-05

[14] "Capacitive level sensor". Level sensor solutions. Elobau

[15] "Operative Principle of a Capacitance Level Sensors" Instrumentation toolbox. 